\title{
$\mathrm{GF} / \mathrm{PE}$ 복합재료의 충격파괴거동에 관한 연구
}

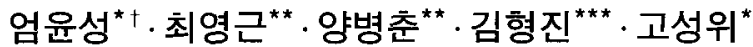 \\ "부경대학교, ${ }^{* *}$ 부경대학교 대학원, ${ }^{* * *}$ 경상대학교 해양산업연구소
}

\section{A Study on the Impact Fracture Behavior of Glass Fiber Polyethylene Composites}

\author{
Yoon-Sung $\mathrm{UM}^{*}$, Young-Kuen $\mathrm{CHOI}^{* *}$, Byeong-Chun $\mathrm{YANG}^{* *}$ \\ Hyung-Jin $\mathrm{KIM}^{* * *}$ and Sung-Wi $\mathrm{KOH}^{*}$ \\ * Pukyong National University, ${ }^{* *}$ Graduate School, Pukyong National University, \\ *** The Institute of Marine Industry, Gyeongsang National University
}

\begin{abstract}
Many of researches regarding mechanical properties of composite materials are associated with humid environment and temperature. Especially the temperature is a very important factor influencing the design of thermoplastic composites. However, the effect of temperature on impact behavior of reinforced composites have not yet been fully explored. An approach which predicts critical fracture toughness Gic was performed by the impact test in this work.

The main goal of this work is to study the effect of temperature and span of specimen supports on the results of Charpy impact test for GF/PE composite.

The critical fracture energy and failure mechanism of GF/PE composites were investigated in the temperature range of $60^{\circ} \mathrm{C}$ to $-50^{\circ} \mathrm{C}$ by the Charpy impact test. The critical fracture energy showed the maximum at the ambient temperature, and it tended to decrease as the temperature increased or decreased from the ambient temperature. The major failure mechanisms are the fiber matrix debonding, the fiber pull-out and/or delamination and the matrix deformation.
\end{abstract}

Keywords : impact test(충격시험), fracture behavior(파괴거동), temperature effect(온도효과), GF/PE composites(유리섬유/폴리에틸렌 복합재료), fracture mechanisms(파괴기구), critical fracture energy (임계파괴에너지), SEM(주사현미경)

\section{서 론}

최근 경량성, 내식성, 절연성 둥의 기계적 특성을 가지고 있는 복합재료가 크게 각광을 받고 있으며, 이러한 복합재료 중에서 섬유강화 복합재료가 널리 사용되고 있다. 섬유강화 복합재료는 경량이기 때문 에 과거에는 단지 구조물의 무게를 경감하기 위해 부 속품으로 사용되었으나 고강도이며 고강성의 성질을
가지는 열경화성 복합재료 ${ }^{1}$ 가 구조물의 주하중을 받 는 주부품으로 사용되기 시작하였다.

Sahnoune 등른 열가소성수지인 HDPE(high density polyethelylene)와 PP에 두가지의 SEBS 탄 성중합체를 혼합하여 만든 복합재료의 충격시험과 인 장시험을 통하여 증가된 충격강도와 인장강도에 대해 보고하였으며, Park과 Jang ${ }^{3)}$ 은 CF/PE복합재료의 섬 유와 수지의 접착강도를 이용하여 성능개선에 대한

${ }^{\dagger}$ Corresponding author : uys0108@hanmail.net 
연구를 하였다. Santulli와 Cantwell ${ }^{4}$ 은 천연섬유와 $\mathrm{PE}$ 를 사용한 복합재료의 수분에 의한 영향을 고찰하 기 위해 충격시험을 통한 충격거동에 관한 연구를 하 였으며, Kinlock와 Steidl ${ }^{5)}$ 은 모든 산업용 수지는 충 격강도의 개선을 위해서는 고무의 상이 혼합된 다 상 의 재료가 되어야 한다고 하였다. Schultz와 Fri$\mathrm{edrich}^{6)}$ 는 GF/PET복합재료는 저온과 고변형률에서 는 매트릭스가 취성파괴되고 섬유가 풀아웃되는 현상 을 보이며 실온에서 보다 기계적 특성이 좋아지며 고 변형률에서는 섬유와 매트릭스계면에 높은 전단 강도 가 발생한다고 하였다. Prichard와 Yang ${ }^{7}$ 은 입자강 화 복합재료에서 주충격 파손모드는 섬유와 매트릭스 사이의 디본딩이라 하였으며 Matheswaran과 Kishore $^{8)}$ 는 에폭시기지 복합재료에서 첨가제의 첨가에 의해 충격저항치가 커지며, 강인한 기구가 달라진다고 하였다. Tomlinson와 Holland ${ }^{9)}$ 는 환경적요인, 즉 염 분과 온도에 대한 $\mathrm{GF} / \mathrm{PP}$ 의 충격거동에 관한 연구를 하였다. 엄 등 ${ }^{10)}$ 은 실온 $-50^{\circ} \mathrm{C}$ 에서 충격실험을 통 하여 충격에너지의 변화와 파괴기구를 규명하였고, Karmaker $^{11}$ 는 jutet 섬유-PP 복합재료의 충격강도 와 수분흡수의 영향에 대해 연구하였으다. Sjogren와 Berglund ${ }^{12)}$ 는 $\mathrm{GF} / \mathrm{PP}$ 의 인장시험과 충격시험을 통해 수지안에서의 유리섬유 거동에 대해서 보고하였으며, Baxter $^{13)}$ 는 단섬유가 무질서하게 배열된 단섬유복합 재료를 3 차원적으로 해석하였다. Schneider 등 ${ }^{14)}$ 은 다양한 구형 고무상입자를 첨가한 열가소성 복합재료 의 충격실험을 통해 입자들이 기계적특성에 미치는 형 향에 대해 연구하였으며, Karmaker와 Prasad ${ }^{15)}$ 는 섬유강화복합재료의 굽힘시험을 통해 시험편 지지길이 의 영향에 대하여 보고하였다. 이처럼 충격강도에 영향 을 미치는 인자에 대한 연구결과는 많지만 섬유함유율 과 지지길이(스팬길이), 환경적요인 중 온도변화에 따 른 충격파괴기구에 대한 고찰은 아직 희박한 실정이다.

따라서 이 연구에서는 열가소성 복합재료의 기계적 특성과 파괴거동에 관한 종합적인 연구의 일환으로 섬유함유율이 $10 \%$ 인 $\mathrm{GF} / \mathrm{PP}$ 복합재료의 충격시험을 통하여 스팬길이를 20,30 그리고 $40 \mathrm{~mm}$ 로 변화하 여 스팬질이의 영향을 고찰하고 $-50^{\circ} \mathrm{C}$ 에서 $60^{\circ} \mathrm{C}$ 사 이의 온도범위에서 각각의 스팬길이에 대한 임계 파 괴에너지의 거동을 고찰하여 온도변화에 따른 스팬의 길이에 대한 영향을 규명하고자 한다.

\section{재료 및 실험방법}

실험에 사용한 복합재료의 매트릭스는 $\mathrm{PE}$ 수지, 강
화섬유로는 유리단섬유 $(2 \sim 4 \mathrm{~mm})$ 를 사용하였으며, 용 융된 $\mathrm{PE}$ 수지에 유리섬유를 혼합하여 인 라인 스크류 (in-line screw)식의 사출기를 사용하여 $3 \mathrm{~mm}$ 의 두 께로 성형하였다. 성형조건은 스크류속도 $60 \mathrm{rpm}, 1$ 차 사출속도 $1200 \mathrm{~kg} / \mathrm{cm}^{2}$ 그리고 2차 사출속도 $900 \mathrm{~kg} / \mathrm{cm}^{20}$ 로 사출 성형하였으며 성형시 수지에 대 한 섬유함유의 체적비는 $10 \%$ 로 성형한 국산 단섬유 국산 단섬유 $\mathrm{GF} / \mathrm{PE}$ 복합재료(현대산업개발(주)) 를 사용하였다. 충격시험은 하중 2.82 25J 그리고 충격 속도 $3.46 \mathrm{~m} / \mathrm{s}$ 인 샬피 충격실험기(Tinius Olsen Model $92 \mathrm{~T}$ )를 이용하여 $20 \mathrm{~J}$ 의 하중과 $3.46 \mathrm{~m} / \mathrm{s}$ 의 충격속도로 실험을 행하였다.

충격 시험편은 시험편 폭 $10 \mathrm{~mm}$, 시헙편 길이가 $55 \mathrm{~mm}$ 그리고 스팬길이 $40 \mathrm{~mm}$ 인 시험편을 나타낸 것으로 원재료에서 다이아몬드 커터를 이용하여 절단 하였고, 이 표면을 밀링에 의하여 가공하였다. 노치는 시험편의 중심에 두께 $1 \mathrm{~mm}$ 인 톱으로 일차 가공한 후, 노치선단이 더욱 날카롭게 하기 위해 신품의 면 도날을 이용하여 총 크랙길이가 $1 \sim 2.25 \mathrm{~mm}$ 의 범위 가 되도록 이차 가공하였다. 시험편 길이가 $35 \mathrm{~mm}$ (스팬길이 $20 \mathrm{~mm}$ ) 와 $45 \mathrm{~mm}$ (스팬길이 $30 \mathrm{~mm}$ ) 인 시 험편도 동일한 방법으로 가공하였다.

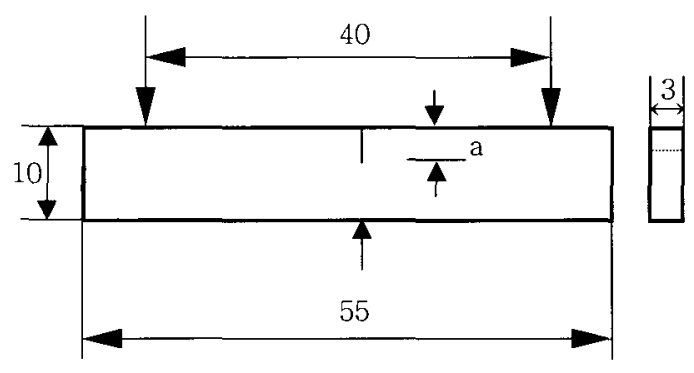

Fig. 1. Specimen geometries for Charpy impact $(\mathrm{mm})$.

충격시험을 위한 시험편의 온도설정을 위해 스테인 리스강과 강화유리로 이루어지고 벽면을 단열처리 한 챔버를 제작하였으며 고온과 저온의 환경조건을 위해 챔버내부의 온도는 $-50^{\circ} \mathrm{C}$ 에서 실온(room tempera ture : R.T.), 실온에서 $60^{\circ} \mathrm{C}$ 사이의 범위에서 변화시 겼다. 고온의 실험시에는 챔버내부에 가열코일(heat ing coil)을 설치하여 내부의 공기를 가열하였으며 챔버내부의 온도분포가 고르게 하기 위하여 팬을 이 용하여 챔버안의 공기를 대류시컸다. 그리고 저온의 
실험시에는 외부에 특수제작된 액체질소통을 부착하 여 액체질소량을 조절하여 챔버안의 공기를 냉각시켰 다. 온도가 저하되면 고온에서처럼 팬을 사용하는 것 이 불가능하므로 액체질소가 챔버안에서 고르게 분포 할 수 있도록 분사 노즐을 가공하여 챔버안에서 냉각 된 공기가 순환하도록 하였으며, 챔버안의 내부온도 는 열전대(thermocouple)로 감지하여 온도제어기로 필요한 설정온도를 $\pm 1^{\circ} \mathrm{C}$ 이내에서 유지시켰다. 설정 온도에 도달하면 시험편의 내부도 표면과 동일한 온 도가 되도록 10 분이상 유지한 후 충격속도 $3.46 \mathrm{~m} / \mathrm{s}$ 인 샬피충격실험기를 이용하여 실험을 행하였다. 충 격시험후 파단면의 미소파괴를 관찰하기 위하여 파면 을 주사현미경(scanning electron microscope : $\mathrm{SEM})$ 을 이용하여 관찰하였다.

임계퐈괴에너자 $\mathrm{G}_{\mathrm{IC}}$ 의 평가는 식 (1)와 같이 충격 시험에서 얻은 파괴에너지 U와 시험편 두께와 시험 편 폭 그리고 무차원 계수의 곱 $\mathrm{BW} \varnothing$ 를 이용하여 최소자승법에 의하여 기울기를 구하여 이 기울기를 임계파괴에너지 $\mathrm{G}_{\mathrm{KC}}$ 로 한 Williams 등ㄱㅇㅣ 이 제안한 방 법으로 계산한 것이다.

$$
U=U_{k}+G_{I C} B W \varnothing
$$

여기서 $U$ 는 총 충격에너지이고, $U_{k}$ 는 운동에너지, $B$ 는 시험편 두께, $W$ 는 시험편 폭 그리고 $\varnothing$ 는 무차원형상계수로서 다음과 같다.

$$
\varnothing=\frac{C}{d C / d(a / W)}
$$

여기서 $C$ 는 컴플라이언스(compliance)이고 $a$ 는 크랙길이이다.

무차원계수 $\varnothing$ 를 다른 방법으로 나타내면 다음과 같다.

$$
\varnothing=\frac{1}{2} \cdot \frac{a}{W}+\frac{1}{18 \pi} \cdot \frac{S}{W} \cdot \frac{1}{a / W}
$$

여기서 $S$ 는 스팬길이이다.

파괴에너지 $U$ 와 $B W \varnothing$ 를 도시화하여 최소자승 법으로 그 기울기를 구하면 이것이 임계파괴에너지 $\mathrm{G}_{\mathrm{IC}}$ 가 된다.

\section{결과 및 고찰}

\section{1. 온도변화}

Fig. 2는 동일한 스팬길이의 조건에서 온도의 변화 에 대한 임계파괴에너지 $\mathrm{G}_{\mathrm{C}}$ 를 나타낸 것으로 $\square$ 는 $60^{\circ} \mathrm{C}, \bigcirc$ 는 실온, $\triangle$ 는 $-15^{\circ} \mathrm{C}$ 그리고 $\nabla$ 는 $-50^{\circ} \mathrm{C}$ 인 경우를 나타내고 있다. 임계파괴에너지 $\mathrm{G}$ 는 식(1) 의 총 파괴에너지와 무차원계수인 $\mathrm{BW} \varnothing$ 의 기울기로 서 산출하였다. 스팬길이가 $20 \mathrm{~mm}$ 인 경우 임계파괴 에너지 $\mathrm{G}_{\mathrm{IC}}$ 의 값은 온도가 실온, $60,-15,-50^{\circ} \mathrm{C}$ 로 변화함에 따라 $0.075,0.063,0.059,0.048 \mathrm{~J} / \mathrm{mm}^{2}$ 을 나타내었다. 이러한 경향은 스팬길이가 $20,30 \mathrm{~mm}$ 인 경우에도 유사한 경향을 보였다. 온도변화에 대한 임 계파괴에너지 $\mathrm{G}_{\mathrm{IC}}$ 의 값들은 스팬길이가 $40 \mathrm{~mm}$ 인 경 우에는 온도의 변화에 따라 수치의 분산이 작으나 스 팬길이가 $30 \mathrm{~mm}$ 그리고 $20 \mathrm{~mm}$ 로 감소함에 따라 온 도의 변화에 대해 수치의 분산이 커지고 있다. 그리 고 온도조건이 실온일 경우의 임계파괴에너지 $\mathrm{G}_{\mathrm{IC}}$ 는 스팬길이의 변화에 따라 거의 선형으로 감소하고 있 으나 온도조건이 $60,-15$ 그리고 $-50^{\circ} \mathrm{C}$ 로 변화할 때의 임계파괴에너지 $\mathrm{G}_{\mathrm{IC}}$ 는 비선형적으로 감소하며, 저온으로 변화할수록 비선형이 증가하고 있다. 따라 서 임계파괴에너지 $\mathrm{G}_{\mathrm{IC}}$ 는 온도를 고온으로 변화시킨 경우보다 온도를 저온으로 변화하였을 때 불안정성이 증가하므로 고온의 영향보다는 저온의 영향을 더 많 이 받고 있음을 알 수 있다.

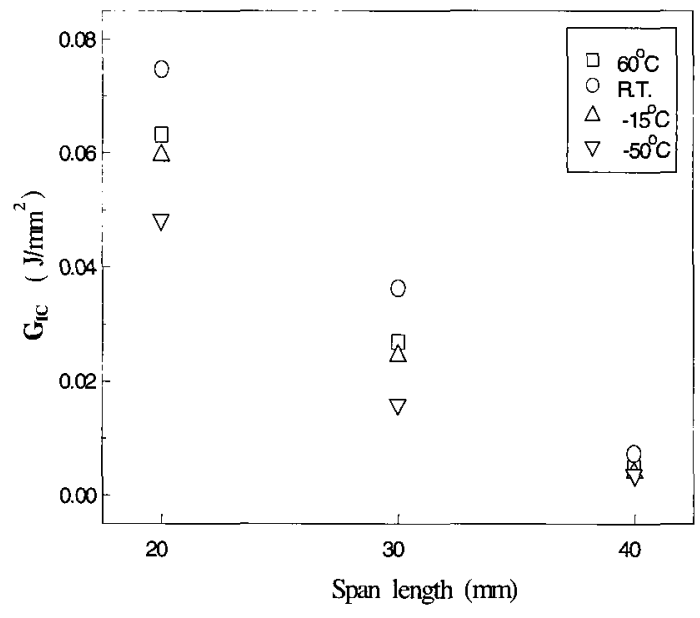

Fig. 2. GIC vs span length for various temperature. 


\section{2. 스팬길이의 변화}

Fig. 3은 실온에서의 스팬길이의 변화에 대한 총 파 괴에너지 U의 값들을 $\mathrm{BW} \varnothing$ 에 대하여 나타낸 것이다. $\square$ 는 $20 \mathrm{~mm}, \mathrm{O}$ 는 $30 \mathrm{~mm}$ 그리고 $\triangle$ 는 $40 \mathrm{~mm}$ 를 나 타내고 있다. 그림에서 총 파괴에너지 $\mathrm{U}$ 는 스팬길이 가 $20 \mathrm{~mm}$ 일 때가 가장 크고, 스팬길이가 $40 \mathrm{~mm}$ 인 경우가 가장 낮게 나타났다. 그러나 스팬길이가 작을 수록 수치의 분산과 불안정성이 증가하고 있다. 이러 한 양상은 $60^{\circ} \mathrm{C},-15^{\circ} \mathrm{C}$ 그리고 $-50^{\circ} \mathrm{C}$ 인 경우에도 유사한 경항을 보였다.

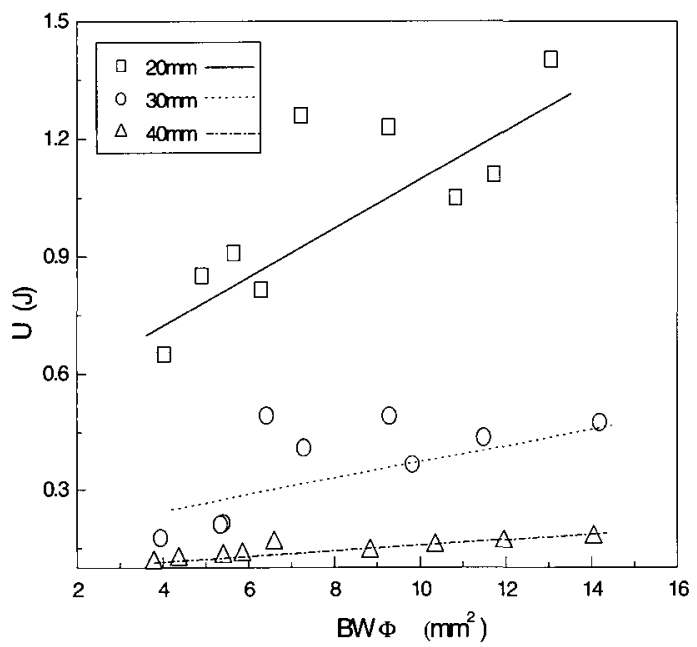

Fig. 3. U vs BW $\Phi$ for various span at ambient.

Fig. 4는 동일한 온도조건에서의 스팬길이의 변화에 대한 임계파괴에너지 $\mathrm{G}_{\mathrm{IC}}$ 를 나타낸 것으로 포기방법 은 Fig. 3, 임계파괴에너지 $\mathrm{G}_{\mathrm{IC}}$ 의 산출은 Fig. 2와 동일하다. 실온에서 임계파괴에너지 $\mathrm{G}_{\mathrm{IC}}$ 의 값은 스팬 길이가 $20,30,40 \mathrm{~mm}$ 로 변화함에 따라 0.075 , $0.036,0.007 \mathrm{~J} / \mathrm{mm}^{2}$ 로 나타났다. 이러한 경향은 $-15^{\circ} \mathrm{C},-50^{\circ} \mathrm{C}$ 그리고 $60^{\circ} \mathrm{C}$ 에서도 값의 차이는 다 소 있지만 유사한 경향을 보였다. 그러나 동일한 온 도조건에서 스팬길이가 $20 \mathrm{~mm}$ 인 경우가 임계파괴에 너지 $\mathrm{G}_{\mathrm{IC}}$ 값이 가장 높게 나타나고 있지만, 스팬길이 가 증가할수록 수치의 변화폭이 감소하고 수치가 안 정된 양상을 보이고 있다. 따라서 스팬길이가 $20 \mathrm{~mm}$ 인 경우에는 수치의 변화폭과 불안정성이 가장 크며, 스팬길이가 증가할수록 변화의 폭과 불안정성이 감소
하므로 스팬길이가 $40 \mathrm{~mm}$ 일 때가 본 연구에서는 적 절한 조건이라 판단된다.

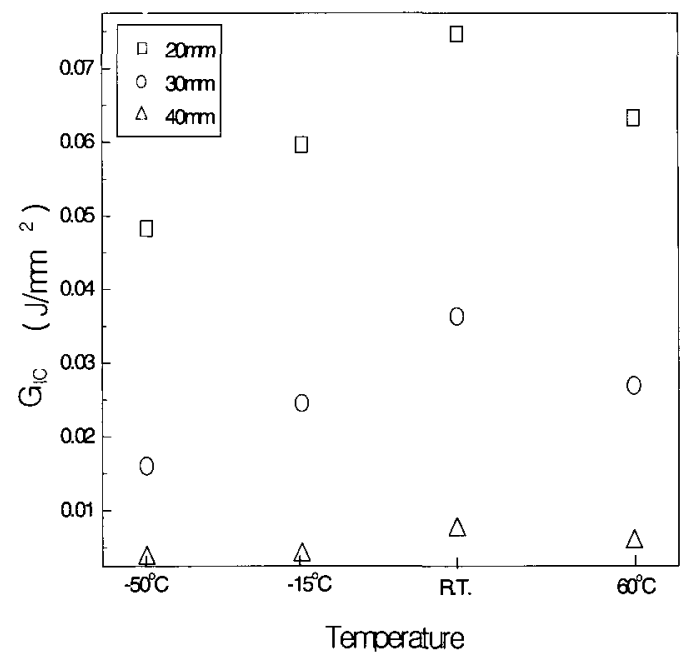

Fig. 4. $\mathrm{G}_{\mathrm{IC}}$ vs various temperature for span length.

\section{3. 파면해석}

Fig. 5는 섬유함유율 $10 \%$, 스팬길이 $20 \mathrm{~mm}$ 인 $\mathrm{GF} / \mathrm{PE}$ 복합재료의 실온에서의 파단면을 파단부위에 따라 나타낸 것으로 (a)는 파단 시작부분, (b)는 파 단면의 중앙부위 그리고 (c)는 파단면의 끝부분을 나 타내고 있다. 그림에서 알 수 있듯이 파단 시작부분 과 파단 끝부분은 중앙부위에 비하여 풀아웃된 섬유 의 길이가 짧게 나타나고 있으며 수지의 파단면도 매 그럽게 파단된 양상을 보이고 있다. 이러한 양상은 스팬길이가 $30 \mathrm{~mm}$ 그리고 $40 \mathrm{~mm}$ 일 때도 유사한 경 항을 보이고 있다. 그리고 온도가 $60,-15$ 그리고 $-50^{\circ} \mathrm{C}$ 인 경우에도 유사한 경향을 보이고 있다.

Fig. 6 은 스팬길이가 $20 \mathrm{~mm}$ 인 $\mathrm{GF} / \mathrm{PE}$ 복합재료의 온도변화에 대한 파괴형상을 보여주는 것으로 (a)는 $60^{\circ} \mathrm{C}$, (b)는 실온, (c)는 $-15^{\circ} \mathrm{C}$ 그리고 (d)는 -5 $0^{\circ} \mathrm{C}$ 의 파단면을 나타내고 있다. 먼저 온도의 변화에 대한 수지의 변형을 비교하여 보면 그림 (b)의 파단 면의 수지형태는 연성과 인성의 영향이 거의 없으며, 그림(a)는 연성과 인성이 증가한 파단형태를 보이고 있다. 이것은 실험에 사용한 $\mathrm{GF} / \mathrm{PE}$ 복합재료의 수지 가 열가소성 수지이므로 온도가 상승하면 연성과 안 성이 증가하는 수지의 고온특성에 의한 것으로 생각 
된다. 그리고 그림 (c)와 (d)를 비교하여보면 그림 (b) 보다 연성과 인성이 감소한 취성파면형태를 보이 고 있다. 이것은 고온의 경우에서와 유사하게 열가소 성수지의 저온특성에 의한 것으로 생각된다. 다음으 로 섬유의 파단형태를 비교하여 보면 그림(b)는 섬유 와 수지사이의 풀아웃(pull out)과 디본딩(debond ing)이 주로 일어나고 섬유의 포면에 남아있는 수지 의 양도 거의 없고 섬유표면도 매끄러운 파괴양상을 보이고 있다. 그림(a)의 파단면은 섬유와 수지의 디 본딩과 섬유의 풀아웃은 그림 (b) 와 유사한 양상을 보 이고 있으나, 그림(b)와 달리 섬유표면에 남아있는 수지의 양도 증가하고 섬유와 수지간의 디본딩이 적 게 발생함을 보이고 있다. 그림 (c)와 (d) 는 풀아웃이 주로 발생하는 양상을 보이고 있으나 그림(d)에 비해 그림(c)는 디본덩이 많이 발생하고 있음을 보여주고 있다. 따라서 온도변화에 대한 인장파괴거동은 온도에
대한 수지의 특성, 디본딩과 풀아웃이 혼합된 복합적 인 파괴양상이라 생각되며 스팬길이가 30 그리고 $40 \mathrm{~mm}$ 인 경우에도 유사한 경향을 보였다.

Fig. 7 은 섬유함유율이 $10 \%$ 인 $\mathrm{GF} / \mathrm{PE}$ 복합재료의 스팬길이의 변화에 대한 파단형상을 나타낸 것으로 (a) 는 $20 \mathrm{~mm}$, (b) 는 $30 \mathrm{~mm}$ 그리고 (c)는 $40 \mathrm{~mm}$ 의 파단면을 나타내고 있다. 그림에서 알 수 있듯이 각 각의 스팬길이의 변화에 대하여 풀아웃과 디본딩이 동시에 나타나고 있으나 스팬길이 $40 \mathrm{~mm}$ 인 경우가 풀아웃과 디본딩이 많이 일어나고 스팬길이가 감소할 수록 수지의 파단면은 매끈하게 파단되어 취성파괴의 형태를 보이며 섬유에 남아있는 수지의 양도 작고 수 지의 변형도 적게 됨을 알 수있다. 따라서 온도의 변 화와 스팬길이의 변화에 대한 충격파괴거동은 수지의 변형과 섬유와 수지의 디본딩 그리고 섬유의 풀아웃이 혼합되어 나타나는 복합적인 파괴양상이라 생각된다

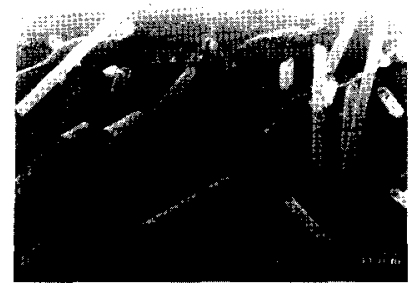

(a) end of notch

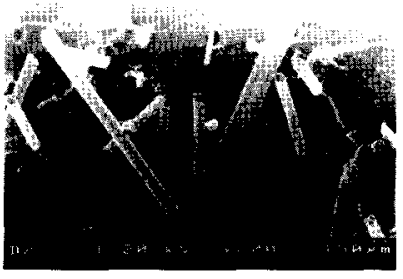

(b) middle of fracture surface
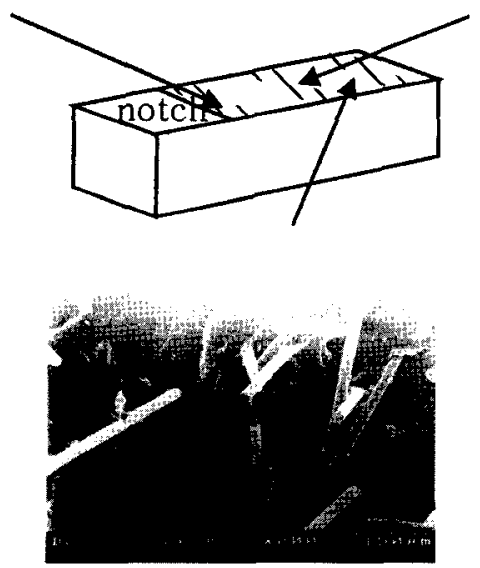

(c) end of fracture surface

Fig. 5. SEM photographs of impact fracture surfaces for $20 \mathrm{~mm}$ span length at room temperature. 


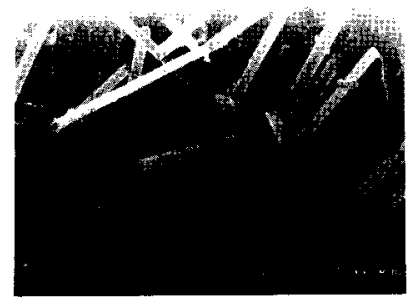

(a) $60^{\circ} \mathrm{C}$

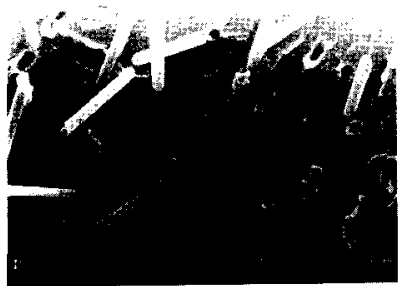

(c) $-15^{\circ} \mathrm{C}$

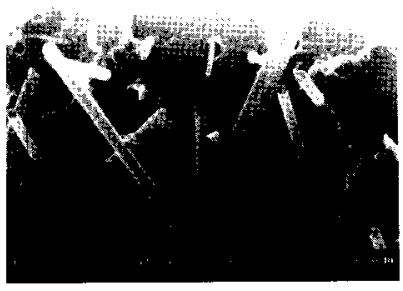

(b) R.T.

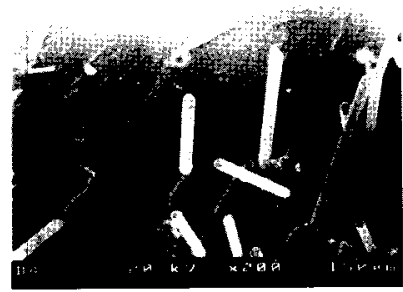

(d) $-50^{\circ} \mathrm{C}$

Fig. 6. SEM photographs of impact fracture surfaces for $20 \mathrm{~mm}$ span length at various temperature.

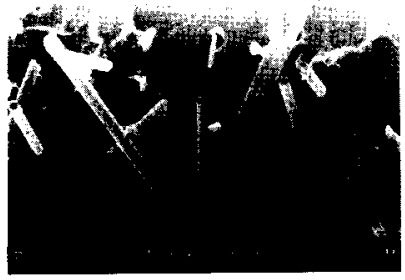

(a) $20 \mathrm{~mm}$

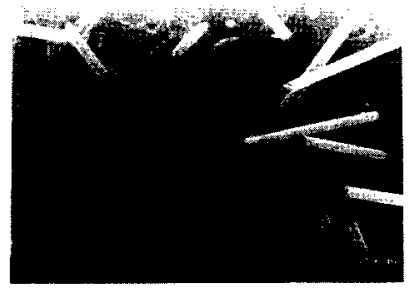

(b) $30 \mathrm{~mm}$

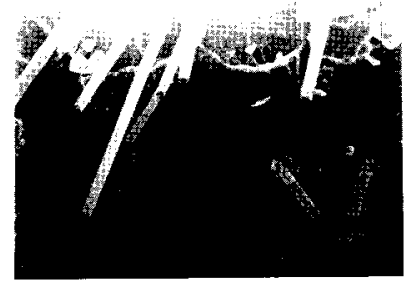

(c) $40 \mathrm{~mm}$

Fig. 7. SEM photographs of impact fracture surfaces for various spa length at room temperature. 


\section{결 론}

본 연구에서는 충격시험을 통해 열가소성 복합재료 의 파괴거동에 영향을 미치는 인자에 대해 검토하였 다. 특히 스팬길이의 변화 그리고 온도의 변화가 충 격파괴강도에 미치는 영향에 대해 고찰하였다.

본 연구의 결과를 요약하면 다음과 같다.

1) $\mathrm{GF} / \mathrm{PE}$ 복합재료의 온도의 변화에 따른 임계파괴 에너지 $\mathrm{G}_{\mathrm{IC}}$ 의 값은 실온에서의 결과가 가장 높게 나타나고 $60,-15$ 그리고 $-50^{\circ} \mathrm{C}$ 순으로 낮게 나타났다.

2) $\mathrm{GF} / \mathrm{PE}$ 복합재료의 스팬길이의 변화에 따른 임계 파괴에너지 $\mathrm{GlC}$ 의 값은 동일한 온도조건하에서는 스팬길이가 $20 \mathrm{~mm}$ 인 경우가 가장 높게 나타났으 나 불안정한 경향을 보였으며, 스팬길이가 $40 \mathrm{~mm}$ 인 경우 임계파괴에너지 $\mathrm{G}_{\mathrm{IC}}$ 의 값은 낮게 나타났으 나 안정된 경향을 나타내므로 스팬길이가 $40 \mathrm{~mm}$ 인 경우의 충격시험편이 본 연구에서는 적절한 조 건이라 생각된다.

3) $\mathrm{GF} / \mathrm{PE}$ 복합재료의 파괴기구는 온도의 변화에 따 라 매트릭스의 변형이 나타났으며 섬유의 풀아웃, 섬유와 매트릭스 사이의 디본딩을 관찰할 수 있 었으며, 이와 같은 파괴기구가 종합적으로 상호작 용한다고 생각된다.

\section{참 고 문 헌}

1) Yue, C. Y. and Cheung, W. L. (1993) : Some Observations on The Role of Transcrystalline Interohase on the Interfacial Strength of Thermoplastic Composites, J. Mat. Sci. Letters, 12, pp. 1092 1094.

2) Sahnoune, F., Lopez-cuesta, J. M. and Crespy, A.(1999) : Effect of Elastomer Interfa cial Agents on Tensile and Impact Proper pies of $\mathrm{CaCO}_{3}$ Filled HDPE, J. Mat. Sci., 34, pp. 534 544.

3) Park, R. and Jang, J.(1999) : Performance Improvement of Carbon fiber / Polyethylen Fiber Hybrid Composites, J. Mat. Sci., 34, pp. 2903 2910.

4) Santulli, C. and Cantwell, W. J. (2001) : Impact Damage Characterization on Jute Reinforced Composites, J. Mat. Sci. Letters, 20, pp. $477 \sim 479$.

5) Korinek, Z. and Steidl, J.(2000) : Impact Properties of Short Fiber Reinforced Polyamide after Different Treatments, J. Mat. Sci. Letters, 19, pp. 729 731.

6) Schultz, J. M. and Friedrich, K.(1984) : Effect of Temperature and Strain Rate on the Strength of a PET/glass Fibre Composite, J. Mat. Sci., 19, pp. 2246 2258.

7) Pritchard, G. and Yang, (1994) : Microscopy of Damage in Particulate-Filled Glass Epoxy Laminate, J. Mat. Sci., 29, pp. 5047 5053.

8) Matheswaran, M. and Kishore, K.(1995) : Static and Impact Behaviour of Thermoplastic Modified Glass Fabric/epoxy Composites, J. Mat. Sci. Letters, 14, pp.951 954.

9) Tomlinson, W. J. and Holland, J. R. (1994) : Pultrusion and Properties of Unidirectional Glass Fibre-Polypropylene Matrix composites, J. Mat. Sci. Letters, 13, pp. 675 677.

10) 엄윤성 - 박기호 - 고성위 · 김형진(1999) : GF/PP 복합재료의 충격파괴거동에 관한 연구, 한국어업 기술 학회지, 35(4), pp.421 427.

11) Karmaker, A. C. (1997) : Effect of Water Absorption on Dimensional Stability and Impact Energy of Jute Fibre Reinforced Polypropylene, J. Mat. Sci. Letters, 16, pp. 462 464.

12) Sjogren, B. A. and Berglund, L. A. (1997) : Failure Mechani는 in Polypropylene with Glass Beads, Polymer Comp., 18(1), pp. 1 8.

13) Baxter, W. J.(1998) : The Correct Interpretation of the Tensile Strength of Short Fibre-Reinforced Composites, J. Mat. Sci. Letters, 33, pp. 5703 5706.

14) Schneider, M., Pith, T. and Lambla, M. (1997) : Thoughening of Polystyrene by Natural Rubber-Based Composite Particles, J. Mat. Sci., 32, pp. 6331 6342.

15) Karmaker, A. and Prasad, A. (2000) : Effect of Design Parameters on the flexural Properties of Fiber-Reinforced Composites, J. Mat. Sci. Letters, 19, pp. 663 665.

2003년 4월 24일 접수 2003년 7월 18일 수리 